ORIGINAL ARTICLE

\title{
Peer buddy mentoring project for nurses' career development
}

\author{
Lauretta Luck*1, Harrison Ng Chok ${ }^{2,3}$, Lesley Wilkes ${ }^{2,3}$ \\ ${ }^{1}$ School of Nursing \& Midwifery, Western Sydney University, Sydney, Australia \\ ${ }^{2}$ Centre for Nursing Research and Practice Development, School of Nursing and Midwifery, Western Sydney University, Sydney, \\ Australia \\ ${ }^{3}$ Nepean Blue Mountains Local Health District, Sydney, Australia
}

Received: August 9, 2017

DOI: $10.5430 /$ cns.v5n4p82
Accepted: September 18, 2017 Online Published: September 26, 2017

URL: https://doi.org/10.5430/cns.v5n4p82

\begin{abstract}
Objective: The aim of the paper is to describe the implementation of a peer buddy mentoring model to support the career development of Registered Nurses (RNs) seeking Clinical Nurse Specialist (CNS) positions.

Methods: A qualitative survey design was used to collect data during the workshops, with follow-up semi-structured telephone or face-to-face interviews. Data were also collected via the researchers' notes.

Results: A total of 32 participants attended the program and 31 completed the surveys. The participants' reported needing more support when applying for a CNS position. Despite these issues, the participants recommend the use of peer buddy mentoring as a motivational, supportive and instructive model.

Conclusions: Peer buddy mentoring, and facilitated workshops, is a relatively low cost and effective strategy to support nurses aspiring to advance their careers. Participants valued the development of the peer buddy relationship and the mutual support and motivation it engendered.
\end{abstract}

Key Words: Buddy, Peer mentoring, Horizontal learning, Clinical nurse specialist, Advanced practice nurse

\section{INTRODUCTION}

Over the past 20 years the development of the clinical nurse specialist grades has provided Registered Nurses (RNs), working in New South Wales (NSW) Australia, with opportunities to expand their professional career. ${ }^{[1]}$ It is important for RNs to have a distinct career pathway to specialist positions that is structured, expands their scope of practice and promotes the attainment of post graduate educational qualifications. ${ }^{[2]}$ In NSW, there are three levels of advanced practice nurses: Clinical Nurse Specialist (CNS); Clinical Nurse Consultant (CNC); and Nurse Practitioner. ${ }^{[3]}$ This structured process allows eligible RNs to progress their careers by re-grading to a CNS role or take a position as a CNC. ${ }^{[4]}$

Attaining the role as a CNS is dependent upon the RN's ability to meet the criteria set by the Public Health System Nurses' and Midwives' (State) Award 2017. ${ }^{[4]}$ The award clearly outlines the criteria for appointment to this advanced practice role. A registered nurse needs 12 months experience working in the specialty area and a post registration certificate, or four years' experience with three years' experience in the specialty area. In addition to meeting the number of

\footnotetext{
*Correspondence: Lauretta Luck; Email: lauretta.luck@westernsydney.edu.au; Address: School of Nursing \& Midwifery, Western Sydney University, Sydney, Australia, Locked Bag 1797, Penrith South DC, NSW, 2751, Australia.
} 
years' nursing experience in the specialty they also need to provide evidence of their contribution to clinical practice, their role as a resource and mentor and provide evidence of activities related to their own professional development. ${ }^{[4]}$ Eligible RNs' need to develop a portfolio of evidence and apply for personal promotion. The application is assessed by the RN's line supervisor and, if successful, approved by the Director of Nursing.

Historically, one way nurses have supported each other for career advancement has been through mentorship. ${ }^{[5]}$ Mentoring is traditionally a vertical mentor-mentee model ${ }^{[6]}$ where the mentor is usually more experienced than the mentee. ${ }^{[7,8]}$ Alternatively, horizontal peer mentoring strategies enable participants of equal level to exchange knowledge and skills and support personal and professional development. ${ }^{[9]}$ Grouping equivalently experienced people to achieve a shared goal leads to increased stimulation, motivation and interdependent learning. [9]

In this study peer buddy mentoring is defined as a form of horizontal mentoring where mentee pairs buddy up to share ideas, strive for a common goal, connect socially and emotionally to further advance their careers. ${ }^{[10]}$ This paper will discuss the lessons learned following the implementation of peer buddy mentoring program to help RNs progress their nursing careers.

\section{Peer buddy mentoring program}

This study was undertaken by inviting interested RN's to two (2) face to face workshops that were two (2) hours in duration and one week apart. The workshops were offered in two locations within the same Local Health District (LHD). The aim of the peer buddy mentoring program was to enable pairs of RN's to form mutually supportive relationships to meet a common goal. In this program, the focus of the RN's work was to develop the portfolio of evidence to use for their promotion. In the first workshop participants were introduced to the peer buddy mentoring project and provided with information to enable them to use the peer buddy mentoring model for their professional development. The workshop included content on reflective practice and maintaining a reflective journal. During this workshop the participants self-selected into buddy pairs or trios. The second workshop focused on supporting the RN's to develop their portfolio of evidence. A Clinical Nurse Educator (CNE), familiar with the Public Health System Nurses' and Midwives' (State) Award, ${ }^{[4]}$ the LHD policies and the application process, presented to the participants and showed them an example of a successful portfolio. The workshop also enabled further discussion of the peer buddy mentoring relationship and participants were encouraged to maintain their journal.
Following workshops 1 and 2 the participants were asked to meet as regularly as their work and time commitments permitted over the subsequent three month period. The purpose of these meetings were to allow peer buddies to develop realistic goals to progress their application portfolio. In between meetings the participants could work towards achieving these agreed upon goals and the participants could help each other refine their portfolio of evidence. Participants were encouraged to meet face-to-face or use telephone and social media. Additionally, each participant was given a reflective journal, asked to keep notes on their meetings and to diarise their mutually agreed future tasks.

\section{METHODS}

A qualitative survey design, using open-ended questions, was used to collect data during the workshops. Survey design is frequently used when little is known about the phenomenon under investigation. ${ }^{[11,12]}$ Surveys are a relatively quick and inexpensive way to obtain self-reported data. Follow-up semi-structured telephone or face-to-face interviews were also part of the research design. Semi-structured interviews allow for a more in-depth exploration of the topic of interest from the participant's perspective. ${ }^{[13]}$ Qualitative data were also collected from the participant's reflective journal and the researchers' notes.

\subsection{Sample}

The sample consisted of 32 RNs who self-selected to be part of the peer buddy mentoring workshops. The researchers attended a Nurse Managers meeting to explain the study and to enlist their support to advertise the project to nursing staff who were eligible to apply to be a CNS. Participants were also recruited via a flyer on the LHD intranet email.

\subsection{Data collection}

There were four occasions where data collection was designed to occur. First was a qualitative survey at the beginning of workshop 1. Second was at the end of workshop 2 where qualitative survey data were also collected. The last two data collection methods involved a follow up face-toface or telephone interview at three months and a telephone interview at six months. The participants were asked to keep a reflective journal that included their personal reflections on the peer buddy relationship and their meetings, what they planned to do for their next meeting and their experiences writing their portfolio of evidence. It was envisaged that the journal would be returned to the researchers six months after the first workshop. Throughout the workshops the researchers took notes of the main issues discussed by the participants. The survey at the beginning of workshop 1 consisted of demographic information and six open ended 
questions. The questions sought the participant's knowledge on mentoring and the peer buddy model (see Table 1). Other questions involved why career progression was important to them. The five questions in the survey given to participants at the end of workshop 2 were designed to collect data about the value of the workshop and how it added to their ability to apply for promotion.

Table 1. Participant knowledge on mentoring and the peer buddy model

\begin{tabular}{|c|c|}
\hline Pre Workshop Open-ended questions & Post workshop Open-ended questions \\
\hline What do you know about mentoring? & $\begin{array}{l}\text { Did the workshop help you understand the role of a peer buddy mentor in } \\
\text { developing your career? } \\
\text { - Please explain }\end{array}$ \\
\hline What do you know about peer buddy mentoring? & What were the key strengths of the peer buddy mentoring workshop? \\
\hline $\begin{array}{l}\text { Have you been involved in a peer buddy mentoring system before? } \\
\text { - If so please explain }\end{array}$ & What were the key weaknesses of the peer buddy mentoring workshop? \\
\hline $\begin{array}{l}\text { What do you know about the process of becoming a Clinical Nurse } \\
\text { Specialist? }\end{array}$ & $\begin{array}{l}\text { How did the workshop help you understand the process of developing your } \\
\text { career to Clinical Nurse Specialist? }\end{array}$ \\
\hline $\begin{array}{l}\text { Is career progression important to you? } \\
\text { - Please explain }\end{array}$ & $\begin{array}{l}\text { Would you recommend the peer buddy mentoring workshop to other } \\
\text { Registered Nurses? } \\
\text { - Please explain }\end{array}$ \\
\hline
\end{tabular}

All participants were followed up at three months by email in order to organise a face-to-face or telephone interview and again at six months for a telephone interview and to organise collection of the reflective journal.

Table 2. Demographics of participants

\begin{tabular}{llll}
\hline Demographics & Details & Number $\mathbf{( N )}$ & Percentage (\%) \\
\hline \multirow{2}{*}{ Gender } & Female & 28 & 87.5 \\
& Male & 4 & 12.5 \\
& 21-30 years & 6 & 18.8 \\
Age in years & 31-40 years & 5 & 15.6 \\
& 41-50 years & 16 & 50.0 \\
& 51-60 years & 5 & 15.6 \\
Years as a nurse & 11-20 & 14 & 43.8 \\
& 21-30 years & 12 & 37.5 \\
& Certificate & 6 & 18.8 \\
& Diploma & 4 & 3.1 \\
& Bachelor & 8 & 12.5 \\
Highest attained & Post Grad Cert & 13 & 25.0 \\
& Post Grad Dip & 1 & 40.6 \\
& Masters & 3 & 3.1 \\
& PhD & 0 & 9.4 \\
& Hospital trained & 1 & 0 \\
& Missing & 1 & 3.1 \\
\hline
\end{tabular}

\subsection{Data analysis}

Workshop $1 \& 2$ surveys were analysed by categorising and counting the participants responses to individual items. Similarly to the work of Wilkes et al., ${ }^{[14]}$ text was manually searched for common words that were categorised and counted. Data were, therefore, decontextualized. ${ }^{[15]}$ The resultant categories reflected common words and ideas. This approach is also supported by Bazeley ${ }^{[16]}$ who asserts that qualitative data can be numerically counted. There was in- sufficient data from the three and six month data collection phases, or the reflective journals, to undertake data analysis. If there was sufficient data from these sources, the same approach to analysis would have applied. Demographic data were entered into SPSS Ver. 22 ${ }^{[17]}$ and analysed descriptively with frequencies and means.

\subsection{Ethics}

Ethics was approved by the LHD where the participants were employed and the relevant University Human Research Ethics Committee. Participant's voluntary informed consent was obtained. All participants were given a participant information sheet that outlined the time commitment for the workshops, the three and six month post workshop interviews, the peer buddy meetings and the request for them to keep a reflective journal. To maintain confidentiality, no identifying information regarding the participants were collected.

\section{RESUltS}

A total of 32 participants attended the program. Thirtytwo participants completed the workshop 1 survey and 31 completed the survey for workshop 2 . The majority of the participants were female $(n=28)$ and there were four male participants. Most of the participants were within the 41-50 year old bracket $(50 \%, n=16), 19 \%(n=6)$ were in the 21-30 year age bracket and five (15\%) were over 51 years of age. Twenty $(62.5 \%)$ of the participants worked full-time and $18(56.3 \%)$ had worked for over 11 years as an RN. The highest level of qualifications was a Master's degree $(n=3)$ with most of the participants holding a Post Graduate qualification $(n=14)$. Demographics of the participants are in Table 2. 
Workshop 1 questions focused on the participants understanding of different styles of support for career progression and explored why these nurses wanted to apply to become a CNS. With respect to the distinction between mentoring and peer buddying, most of the participants were aware of the difference between hierarchical mentoring systems of support ( $\mathrm{n}$ $=20)$ versus horizontal buddies working together $(n=21)$. Quite a few of these nurses were aware of the Public Health System Nurses' and Midwives' (State) Award ${ }^{[4]}$ that underpinned career progression $(n=11)$ and the LHD paperwork and processing arrangements $(\mathrm{n}=10)$. However, only six understood the professional activities and personal attributes they needed to demonstrate in order to be eligible to become a CNS. The majority of the participants $(n=20)$ reported that career progression was important to them. With respect to why career progression was important the majority $(n=20)$ offered explanations that included; increased professional and personal accountability, responsibility, and recognition of knowledge and skills. Six $(n=6)$ mentioned the length of time they had been working as an RN. Notably $(n=22)$ participants volunteered for the workshop because they wanted support to progress their careers. Only one $(n=1)$ reported they were encouraged to attend by their nurse manager.

The goals of workshop 2 included providing information on the processes and personal activities needed to become a CNS. This was achieved by continuing to nurture and support the peer buddy relationships that had been developing and by inviting a CNE to present to the group. Eighteen $(n=18)$ reported a strength of the workshop was the peer and researcher support and eleven $(n=11)$ reported that the strength of the workshop was the presentation by the CNE. Most of the participants $(n=23)$ left the question "what were the weakness of the workshop" blank. Other responses included that the CNE session was too short $(\mathrm{n}=2)$, difficulty with peer buddy $(\mathrm{n}=3)$ and lack of time $(\mathrm{n}=3)$. Overwhelmingly the participants $(n=31)$ would recommend the workshops to other RNs reporting that the advice regarding the requirements, evidence and process of application $(n=24)$ helped them to understand how to apply to become a CNS. At the end of workshop 2, participants' understanding of the peer buddy mentoring system had changed, reporting they understood the role of peer buddy mentoring $(n=31)$. The participants indicated that the workshop encouraged them to work with a peer $(\mathrm{n}=11)$ and helped to clarify the peer buddy process $(n=8)$ however one participant felt the workshop was not helpful because of their peer buddy relationship but did not provide any additional detail.

There were three main ideas derived from the researchers' notes. There were many participants' comments, recorded by the three researchers, regarding feeling that there was not enough support when applying for CNS level. This included participants stating that the opportunities needed to enable them to lead appropriate activities on the wards (such as mentoring student nurses, running in-service education programs) were not offered to them but given to younger staff members. Participants also discussed the complexity of the application, in particular the supporting evidence that they needed to provide. Further adding to this was the difficulty they had accessing the LHD intranet to find the application forms and related information. Finally, the participants reported that the workshops and the peer buddy mentoring helped them, were motivating and informative.

Only three participants responded to the three month contact, no participants responded to the six month contact and only one reflective journal was returned, therefore there were insufficient data to report.

\section{Discussion}

Our study supports the assertion that nurses are interested in progressing their careers however they need additional support to be successful. ${ }^{[18,19]}$ This support can be provided by the RN's supervisor, the CNE or other RN's working at an equivalent level of experience. It is part of the role of the nurse supervisor to encourage their team to engage in on-going education, make a contribution to nursing practice and support their career aspirations. ${ }^{[19]}$ Our study suggests that these nurses, mostly with over 11 years clinical experience, believed that because of their years nursing experience they were no longer given opportunities by their supervisor to engage in activities that would support their career aspirations. Availing staff the opportunities to engage in professional development has been found to improve job satisfaction and intention to stay in nursing. ${ }^{[20]}$ It is important to note that the supervisors of these nurses enabled the participants' professional development by allowing them to attend the workshops in work hours. In conjunction with working outside of working hours, having opportunities while at work to specifically address career aspirations is needed for RNs to successfully access the resources needed to complete applications for career progression.

Horizontal mentoring has been used extensively in nursing. ${ }^{[5,21]}$ Traditionally nurses are formally or informally assigned to act as a mentor and usually the mentor has more experience than the mentee. ${ }^{[8]}$ This style of mentoring is often applied to support less experienced RN's and student nurses. ${ }^{[22]}$ While Mariani ${ }^{[21]}$ found that mentoring does not influence nurse's decision to stay in the profession, it has been found to be a good organisational strategy to support nurses' job satisfaction, provide education and guidance and to enable career progression. In addition to formal mentoring 
programs, our work demonstrates the efficacy of using a horizontal, peer buddy mentoring relationship to help RN's meet their career aspirations that is not dependent on an unequal relationship.

Creating a workshop environment and developing a rapport with the participants provides a supportive structured approach for nurses to be able to set goals, discuss common concerns, solve shared problems and address the requirements to enable them to be promoted. This was fostered by the presentation provided by the CNE. Providing a dedicated time for nurses to reflect on their personal goals, experience and achievements was seen as a positive opportunity to assist with career progression. Additionally, using a number of methods concurrently was valued by the participants. Interestingly while the participants valued the face-to-face workshop activities, their engagement in the research arm of the project was limited.

Nurse's engagement with research in the clinical setting is fraught with barriers. ${ }^{[23]}$ Many studies suggest that nurses do not actively participate in research activities in the clinical setting. This is due to a number of challenges such as finding time in busy clinical settings to engage in research, their perceived lack of skills with the research process and lack of support. ${ }^{[24,25]}$ In our study the RN's readily completed the research component of the project during the workshops, however they did not engage in the ongoing data collection phases.

\section{Limitations}

The main limitation in the study was the difficulty getting follow up from nurses after the workshops however, as previously stated, this is not unusual. Despite repeated follow up telephone and email contact, the participants did not return calls or emails. A further limitation was the absence of returned reflective journals impacting on our understanding of the participants' ongoing commitment to, and experience of, the peer buddy mentoring relationship. The age of the participants could also be argued to be a limitation, however their age reflects the demographics of nurses working in NSW. While these limitations are apparent the process and workshops were a success, as evidenced by the nurses' evaluations.

\section{Conclusions}

As an approach to supporting nurses' career aspirations, peer buddy mentoring is relatively cost-effective strategy requiring minimal resources and negligible disruption to clinical services. The success does depend on focused facilitation of the workshops and expertise regarding policy and documentation from nurses such as a CNE. It provides nurses aspiring to develop their careers the opportunity to complete the requirements for their application and simultaneously provide support to a peer.

\section{CONFLICTS OF INTEREST DisClosure}

The authors declare they have no conflicts of interest.

\section{REFERENCES}

[1] Duffield CM, Gardner G, Chang AM, et al. Advanced nursing practice: a global perspective. Collegian. 2009; 16(2): 55-62. PMid: 19583174. https://doi.org/10.1016/j.colegn.2009.02.0 01

[2] Raines CF, Taglaireni ME. Career Pathways in Nursing: Entry Points and Academic Progression. Online Journal of Issues in Nursing. 2008 Sept; 13(3): Manuscript 1.

[3] Luck L, Wilkes L, O'Baugh J. Treading the clinical pathway: a qualitative study of advanced practice nurses in a local health district in Australia. BMC Nursing. 2015; 14(1): 52. PMid: 26500448. https://doi.org/10.1186/s12912-015-0105-7

[4] Industrial Relations Commission of New South Wales. Public Health System Nurses' and Midwives' (State) award 2017. Sydney; 2017 June. Report No.: IRC 00185740.

[5] Mark S, Link H, Morahan P, et al. Innovative mentoring programs to promote gender equity in academic medicine. Acad Med. 2001; 76: 39-42. PMid: 11154192. https://doi.org/10.1097/00001888 -200101000-00011

[6] Raabe B, Beehr TA. Formal mentoring versus supervisor and coworker relationships: differences in perceptions and impact. $\mathbf{J}$. Organiz. Behav. 2003; 24: 271-293. https ://doi.org/10.1002/ job. 193
[7] Palepu A, Friedman R, Barnett R. Junior faculty members' mentoring relationships and their professional development in U.S. medical schools. Acad Med. 1998; 73: 318-323. PMid: 9526459. https ://doi .org/10.1097/00001888-199803000-00021

[8] Bussey-Jones J, Bernstein L, Higgins S. Repaving the road to academic success: The IMeRGE approach to peer mentoring. Acad Med. 2006; 81: 674-679. PMid: 16799297. https://doi.org/10.109 7/01.ACM. 0000232425.27041 .88

[9] Parker P, Hall DT, Kram KE. Peer coaching: A relational process for accelerating career learning. Academy of Management Learning \& Education. 2008; 7(4): 487-503. https ://doi.org/10.5465/AM LE. 2008.35882189

[10] Varkey P, Jatoi A, Williams A, et al. The positive impact of a facilitated peer mentoring program on academic skills of women faculty. BMC Medical Education. 2012; 12(1): 14. PMid: 22439908. https://doi.org/10.1186/1472-6920-12-14

[11] Keough VA, Tanabe P. Survey research: An effective design for conducting nursing research. Journal of Nursing Regulation. 2011; 1(4): 37-44. https ://doi .org/10.1016/S2155-8256 (15)30315-X

[12] Siedlecki SL, Butler RS, Burchill CN. Survey Design Research: A Tool for Answering Nursing Research Questions. Clinical Nurse Specialist. 2015; 29(4): E1-E8. PMid: 26053608. https : //doi.org/ $10.1097 /$ NUR . 0000000000000134 
[13] Creswell JW, Klassen AC, Clark VLP, et al. Best practices for mixed methods research in the health sciences. Bethesda (Maryland): National Institutes of Health. 2001; 2094-2103.

[14] Wilkes L, Cowin L, Johnson M. The reasons students choose to undertake a nursing degree. Collegian. 2015; 22(3): 259-265. PMid: 26552196. https://doi.org/10.1016/j. colegn.2014.01.0 03

[15] Morgan DL. Qualitative content analysis: a guide to paths not taken. Qualitative Health Research. 1993; 3(1): 112-121. PMid: 8457790. https://doi.org/10.1177/104973239300300107

[16] Bazeley P. Issues in mixing qualitative and quantitative approaches to research. Paper presented at: 1st International Conference - Qualitative Research in Marketing and Management University of Economics and Business Administration. Vienna: AUT; 2002 April 10.

[17] IBM Corp. IBM SPSS Statistics for Windows. IBM Corp.: Armonk, NY; 2013.

[18] Adeniran RK, Bhattacharya A, Adeniran AA. Professional excellence and career advancement in nursing: A conceptual framework for clinical leadership development. Nursing Administration Quarterly. 2012; 36(1): 41-51. PMid: 22157789. https ://doi .org/10 .1097/NAQ. Ob013e31823b0fec

[19] Donner G, Wheeler M. Career planning and development for nurses: the time has come. International Nursing Review. 2001; 48(2): 7985. PMid: 11407466. https ://doi.org/10.1046/j.1466-765 $7.2001 .00028 . \mathrm{x}$
[20] Fusilero J, Lini L, Prohaska P, et al. The career advancement for registered nurse excellence program. Journal of Nursing Administration. 2008; 38(12): 526-531. PMid: 19060641. https: //doi.org/10.1097/NNA.0b013e31818ebf06

[21] Mariani B. The effect of mentoring on career satisfaction of registered nurses and intent to stay in the nursing profession. Nursing Research and Practice. 2012 Feb; 1-9.

[22] Block LM, Claffey C, Korow MK, et al. The value of mentorship within nursing organizations. Nursing Forum. Wiley Online Library; 2005.

[23] Brown CE, Ecoff L, Kim SC, et al. Multi-institutional study of barriers to research utilisation and evidence-based practice among hospital nurses. Journal of Clinical Nursing. 2010; 19(13-14): $1944-$ 1951. PMid: 20920021. https://doi.org/10.1111/j.1365-2 $702.2009 .03184 . x$

[24] Luck L, Ng Chok H, Wilkes L. Nurses as participants in research: an evaluation of recruitment techniques. Nurse Researcher. 2017 Sept; 25(2): 1-9.

[25] Akerjordet K, Lode K, Severinsson E. Clinical nurses' attitudes towards research, management and organisational resources in a university hospital: part 1. Journal of Nursing Management. 2012; 20(6): 814-823. PMid: 22967299. https ://doi.org/10.1111/j.1365 $-2834.2012 .01477 . \mathrm{x}$ 